\title{
ANÁLISE E DIAGNÓSTICO DA ACESSIBILIDADE NO MOODLE PARA DEFICIENTES VISUAIS
}

\author{
E.C.LEMOS, I.F.CAVALCANTE ${ }^{1}$, R.P.B. ALMEIDA \\ Instituto Federal de Educação, Ciência e Tecnologia do Rio Grande do Norte ${ }^{1}$ \\ ORCID ID: https://orcid.org/0000-0002-1783-9879 \\ ilane.cavalcanti@ifrn.edu.br ${ }^{1}$
}

DOI: 10.15628/holos.2020.9219

\section{RESUMO}

O presente trabalho trata de uma análise sobre a acessibilidade para estudantes com deficiência visual em cursos na modalidade EaD do IFRN. A Educação a Distância do Campus Natal Zona Leste utiliza prioritariamente o Moodle como Ambiente Virtual de Aprendizagem (AVA) e materiais didáticos específicos para cada curso. Atualmente, vários cursos de graduação e pós-graduação na modalidade EaD do campus têm estudantes com deficiência visual (DV). Neste artigo foram realizadas algumas fundamentações teóricas iniciais acerca de acessibilidade em ambientes virtuais e foram realizados dois testes. O primeiro teste utilizando a ferramenta WAVE e o segundo teste com uma aluna de graduação com DV. Os resultados foram cruzados e analisados culminando em algumas recomendações para o design educacional dos cursos no trabalho com alguns dos recursos e atividades mais utilizados no âmbito do IFRN.

PALAVRAS-CHAVE: acessibilidade no Moodle, WAVE, NVDA, educação a distância, educação inclusiva.

\section{ANALYSIS AND DIAGNOSIS OF MOODLE ACCESSIBILITY FOR VISUALLY IMPAIRED STUDENTS}

\begin{abstract}
This paper deals with an analysis of accessibility for students with visual impairment in IFRN distance education courses. The distance education of Natal Zona Leste Campus uses Moodle as an Virtual Learning Environment (VLE) as well as specific teaching materials for each course. Currently, several undergraduate and postgraduate courses in IFRN distance education have been receiving students with visual impairment (DV). In this article some initial theoretical foundations were
\end{abstract}

made about the inclusion of people with disabilities and their accessibility in virtual environments. The article brings the result of an experiment in which two tests were performed. The first test using the WAVE tool and the second test with an undergraduate student with DV The results were crossed and analyzed culminating in some recommendations for the educational design of the courses at work with some of the resources and activities most used in distance education offered by IFRN.

KEYWORDS: accessibility in Moodle, WAVE, NVDA, distance education, inclusive education. 


\section{INTRODUÇÃO}

Este artigo se constitui como resultado parcial da pesquisa desenvolvida pelo grupo Multirreferencialidade, Educação e Linguagem (GPMEL) do Instituto Federal de Educação, Ciência e Tecnologia do Rio Grande do Norte (IFRN). O grupo vem desenvolvendo projetos ligados à questão da inclusão e da acessibilidade desde o ano de 2018. O primeiro projeto, intitulado "Desenvolvimento da acessibilidade didático-pedagógica na EaD do IFRN: diagnóstico e produção de tópicos de orientação para ambientes virtuais de aprendizagem e materiais didáticos" foi aprovado em âmbito institucional e teve como bolsista de pesquisa uma estudante com deficiência visual (DV) da Licenciatura em Espanhol na modalidade a distância do Campus Zona Leste. Chamo a atenção para o fato de que a estudante é colaboradora, auxiliando as pesquisadoras a identificar os aspectos que contribuem e os que ainda carecem de melhor adaptação na plataforma virtual utilizada nos cursos a distância do IFRN: o Moodle. Essa colaboração, no âmbito do projeto desenvolvido, foi apresentada em evento e publicada em formato de artigo em coautoria com a estudante bolsista. ${ }^{1}$

Ao longo do ano de 2018, o grupo observou que as questões de inclusão e acessibilidade ainda são aspectos emergentes nas práticas docentes e na organização das estruturas didáticas dos cursos EaD do IFRN e decidiu ampliar o escopo da pesquisa, submetendo o projeto "Tecnologias Assistivas na Educação a Distância nos Institutos Federais da Região Nordeste" aprovado pelo Edital MCTIC/CNPq 2018 - UNIVERSAL. É no âmbito desse novo projeto que a pesquisa ora apresentada se desenvolve.

Para dar desenvolvimento a este texto, faz-se necessário, em um primeiro momento, compreender os conceitos de acessibilidade e o papel da modalidade EaD no âmbito do IFRN e na formação, acesso e permanência dos estudantes com deficiência à educação. À reflexão conceitual, segue-se uma análise técnica da plataforma Moodle e de suas adequações ao uso pelos estudantes com deficiência visual, foco deste texto. Por fim, a análise da usabilidade a partir da experiência da colaboradora da pesquisa, estudante com DV de ensino superior, do Campus Zona Leste do IFRN.

\section{ACESSIBILIDADE E A MODALIDADE EAD: ALGUMAS CONSIDERAÇÕES}

A modalidade a distância, em sua essência, demanda uma determinada autonomia do aluno na construção do conhecimento. Essa autonomia exige adaptações relativas à diversidade

\footnotetext{
${ }^{1} \mathrm{O}$ artigo escrito com a colaboração da bolsista de pesquisa foi apresentado no XV Congresso Brasileiro de Ensino Superior a Distância \IV Congresso Internacional de Ensino Superior a Distância (ESUD, 2018). Cf.: NASCIMENTO, L. M. da S.; LEMOS, E. das C.; MOTTA, T. C.; CAVALCANTE, I. F. Adaptação pedagógica em curso da modalidade a distância: garantindo a permanência de estudantes com deficiência visual. Disponível em https://jems.sbc.org.br/PS.cgi/188458.1.pdf?m=188458\&fi=1\&f=188458 1.pdf
}

HOLOS, Ano 36, v.4, e9219, 2020 
de necessidades, de objetivos e de experiências dos indivíduos partícipes dos processos educacionais, sejam professores ou estudantes. Essas adaptações são ainda mais necessárias quando se remete à acessibilidade das pessoas com deficiência, cuja presença vem sendo sentida com mais ênfase a partir da legislação que garante a sua inserção nos sistemas regulares de ensino.

A Constituição Federal incorporou como preâmbulo ao seu texto, a Convenção sobre os Direitos das Pessoas com deficiência, aprovado pelo Decreto Legislativo № 186. O texto dessa convenção, assinado por representantes de vários países, em Nova lorque, busca reconhecer

[...] que a deficiência é um conceito em evolução e que a deficiência resulta da interação entre pessoas com deficiência e as barreiras devidas às atitudes e ao ambiente que impedem a plena e efetiva participação dessas pessoas na sociedade em igualdade de oportunidades com as demais pessoas. (BRASIL, 2008).

Em 2015, é promulgada a Lei 13.146/2015 (Lei Brasileira de Inclusão - LBI), que trata da Inclusão da Pessoa com Deficiência (Estatuto da Pessoa com Deficiência), que, em seu Art. 2으, considera como pessoa com deficiência "aquela que tem impedimento de longo prazo de natureza física, mental, intelectual ou sensorial, o qual, em interação com uma ou mais barreiras, pode obstruir sua participação plena e efetiva na sociedade em igualdade de condições com as demais pessoas." (BRASIL, 2015).

Entre outros aspectos, a Lei da Inclusão defende, em seu Capítulo IV, Art.27, o Direito à educação para as pessoas com deficiência, "em todos os níveis e aprendizado ao longo de toda a vida, de forma a alcançar o máximo desenvolvimento possível de seus talentos e habilidades físicas, sensoriais, intelectuais e sociais, segundo suas características, interesses e necessidades de aprendizagem".(BRASIL, 2008).

Dessas questões, emerge o conceito de acessibilidade, que consiste em práticas inclusivas para permitir o acesso de todos, possibilitando uma vida independente, participação e acesso plenos, assim como igualdade de oportunidades em sociedade. A acessibilidade é um processo que visa identificar e eliminar as barreiras existentes em todas as dimensões sejam elas: atitudinais, físicas, tecnológicas, comunicacionais, informacionais, linguísticas, pedagógicas entre outras, com a finalidade de garantir à pessoa com deficiência o direito de ir e vir e de estar inserida no mundo do trabalho, de ser um cidadão atuante nos diversos âmbitos sociais, exercendo atividades e funções e assim poder influenciar no desenvolvimento e evolução da sociedade

Estando a inserção das pessoas com deficiência às instituições de ensino asseguradas por lei, resta saber como garantir a sua permanência e êxito, posto que isso depende da capacidade das instituições em atender de forma adequada às diferentes necessidades dos indivíduos, seja por meio do atendimento e acompanhamento realizado por profissionais adequados, seja por meio da adaptação arquitetônica dos ambientes, ou mesmo da adaptação dos materiais didáticos, enfim, em todos os aspectos necessários a seu aprendizado. 
Dentro da rede federal, o IFRN é pioneiro na implantação de cotas sociais na rede de Educação Profissional, Científica e Tecnológica (EPCT) (SKEETE, 2013) e tem importante política de assistência estudantil. Mas, a implementação da lei n.12.711/2012 e a expansão da instituição têm reconfigurado as necessidades de acompanhamento do acesso e permanência dos estudantes.

Em 2012, o IFRN institucionaliza, por meio da Portaria №1533, de 21/05/2010, o Núcleo de Apoio às Pessoas com Necessidades Educacionais Específicas (NAPNE), grupo de trabalho presente em cada campus da instituição e vinculado à Pró-reitoria de Ensino e às Diretorias Acadêmicas de cada campus. Esse núcleo foi instalado no bojo das mudanças desenvolvidas a partir do Programa TECNEP (Educação, Tecnologia e Profissionalização para Pessoas com Necessidades Educacionais Especiais) desenvolvido pela Secretaria de Educação Especial (SEESP) e pela Secretaria de Educação Profissional e Tecnológica (SETEC) do Ministério da Educação e Cultura (MEC) a partir do ano de 2000 tendo, entre suas finalidades, desenvolver uma política pública inclusiva que criasse condições de acesso aos cursos oferecidos pela Rede Federal de Educação Profissional e Tecnológica aos estudantes com necessidades educacionais especiais, garantindo-Ihes a inserção no mundo do trabalho.

Os NAPNE possuem, no IFRN, o objetivo de

Difundir a prática educativa democrática e a inclusão social como diretriz do IFRN. Promover as condições necessárias para o ingresso e permanência de alunos com necessidades educacionais específicas. Promover e participar de estudos, discussões e eventos sobre a inclusão social. Integrar os diversos segmentos que compõem a comunidade do IFRN por meio de ações de sensibilização que favoreçam a corresponsabilidade na construção da ação educativa de inclusão social na Instituição. Atuar nos colegiados dos cursos, oferecendo suporte no processo de ensino e aprendizagem dos discentes. Potencializar o processo ensino e aprendizagem por meio de orientação dos recursos de novas tecnologias assistidas, inclusive mediando projetos de inovação tecnológica assistida, desenvolvidos por discentes e docentes. Propor e acompanhar ações de eliminação de barreiras arquitetônicas, educacionais e atitudinais na instituição. Incentivar a implantação de conteúdo, disciplinas permanentes e/ou optativas referentes à Educação Inclusiva, nos cursos ofertados pelo IFRN. Atuar junto aos professores na adaptação e produção dos materiais didáticos e apoiar os servidores no atendimento de pessoas com necessidades educacionais específicas no ambiente escolar. Promover e estimular o desenvolvimento de atividades formativas para a comunidade educativa do IFRN. Articular as atividades desenvolvidas com as ações de outras Instituições voltadas ao trabalho com pessoas com necessidades educacionais específicas. (IFRN, 2019).

Os NAPNE, portanto, têm a importante função de oferecer o suporte necessário à permanência e ao êxito dos estudantes com deficiência presente em cada campus do IFRN, para isso, devem contar com a presença de profissionais capacitados para essa atuação. O Campus Zona Leste conta com um NAPNE, no entanto, é bom deixar evidente que até o ano de 2019, quando do desenvolvimento deste estudo, o coordenador do NAPNE contava apenas com $2 \mathrm{~h}$ semanais para atuação no âmbito do núcleo e os demais componentes do núcleo não contavam com carga horária para essa demanda de trabalho. Esse núcleo também não contava com um espaço físico para atendimento aos estudantes do campus. Por se tratar de um campus cuja principal oferta tem sido HOLOS, Ano 36, v.4, e9219, 2020 
na modalidade a distância, o NAPNE contava com uma página na plataforma Moodle, principal forma de contato dos estudantes com deficiência para dar vazão às suas demandas, além, é claro, das coordenações de seus respectivos cursos.

Os estudantes de Educação a Distância do IFRN utilizam a plataforma Moodle como principal meio de contato e interação com a instituição. Este Ambiente Virtual de Aprendizagem é o adotado no IFRN para oferta de cursos também na modalidade presencial, ensino híbrido e outras experiências metodológicas. A plataforma Moodle é um recurso que pode ser adaptado para diversos tipos de necessidades, mas ele é a sala de aula do estudante, a partir da plataforma, cada estudante tem acesso ao material didático postado pelos professores e/ou tutores. Esse material didático também exige acessibilidade. Nesse sentido, é relevante a adaptação do material postado e demais tecnologias em relação a pessoas com deficiência visual ou auditiva. 0 artigo 3ㅇ, inciso III da LBI reforça a definição de tecnologia assistiva (ou ajuda técnica) como:

produtos, equipamentos, dispositivos, recursos, metodologias, estratégias, práticas e serviços que objetivem promover a funcionalidade, relacionada à atividade e à participação da pessoa com deficiência ou com mobilidade reduzida, visando à sua autonomia, independência, qualidade de vida e inclusão social;

Dessa forma, a pesquisa aqui apresentada se orienta no sentido de compreender melhor a estrutura que os estudantes de EaD do Campus Natal Zona Leste do IFRN têm acesso e suas dificuldades em interagir com essa plataforma visando a sua autonomia e independência. Para isso, fundamenta-se no conceito de adaptação curricular definido legalmente, no Brasil, a partir dos Parâmetros Curriculares Nacionais: Adaptações Curriculares (BRASIL, 1998, p. 33), como [...] possibilidades educacionais de atuar frente às dificuldades de aprendizagem dos alunos. No sentido de construir as adaptações curriculares, os PCN propõem

que se realize a adaptação do currículo regular, quando necessário, para torná-lo apropriado às peculiaridades dos alunos com necessidades especiais. Não um novo currículo, mas um currículo dinâmico, alterável, passível de ampliação, para que atenda realmente a todos os educandos. Nessas circunstâncias, as adaptações curriculares implicam a planificação pedagógica e as ações docentes fundamentadas em critérios que definem o que o aluno deve aprender; como e quando aprender; que formas de organização do ensino são mais eficientes para o processo de aprendizagem; como e quando avaliar o aluno. (BRASIL, 1998, p. 33),

O conceito de adaptação curricular, portanto, a partir desse marco documental, é bastante amplo e vem sendo desenvolvido nos vários níveis e modalidades de ensino, como indica Aranha (2002). As Orientações Curriculares Nacionais (2008, p. 95) defendem que a eficácia de projetos inclusivos seria construída por uma ação que abarca

Capacitação de professores; engajamento de escolas no processo de inclusão; preparação dos pais dos alunos; preparação dos funcionários; recursos condizentes com os propósitos do projeto; cursos 
de licenciatura em universidades e faculdades atualizadas e sintonizadas com a proposta de inclusão; adequação do currículo escolar às necessidades atuais da sociedade (BRASIL, 2008, p. 95).

Percebe-se, a partir desse documento, que a inclusão e a permanência dos estudantes com deficiência implicam em inúmeras mudanças no âmbito educacional. O processo de inclusão, nesse sentido, envolve a reestruturação das culturas, das políticas e das práticas das escolas que, como sistemas abertos, precisam repensar suas ações, até então predominantemente excludentes.

Portanto, consideramos essencial desenvolvermos tal adaptação, a partir das necessidades mais específicas da modalidade de Educação à Distância. Além disso, conforme Schlünzen Júnior e Hernandes (2011, p. 70), ao tratar sobre a acessibilidade de pessoas com deficiência visual:

[...] cabe ressaltar que eliminar as barreiras que impedem a inclusão da PDV [pessoas com deficiência visual] à educação e ao mundo do trabalho requer esforços tanto por parte das PDV, quanto pelas instituições de ensino profissionalizante, bem como da sociedade empresarial. É preciso modificar procedimentos e estruturas para adaptar o meio às necessidades das PDV sem, contudo, modificar seus objetivos, garantindo que todos não percam sua identidade.

Os autores advertem a necessidade de que é possível para as instituições serem flexíveis de forma a poder mudar seus objetivos, adaptar suas metodologias, reorganizar procedimentos e redefinir estruturas sem perder sua identidade e garantindo a inserção, a permanência e o êxito dos estudantes com deficiência.

Esta pesquisa se volta para a realidade do Campus Natal Zona Leste do IFRN, que tem recebido estudantes com deficiência visual na oferta de seus cursos a distância, buscando realizar uma primeira análise do ambiente virtual, dos materiais e das tecnologias utilizadas em cursos da modalidade a distância para indicar possíveis adaptações com o intuito de sanar eventuais barreiras de inclusão como será detalhado nos tópicos posteriores.

Em um primeiro tópico analisa-se o Moodle adaptado pelo IFRN para cursos a distância por meio do aplicativo WAVE, a seguir, descreve-se o teste realizado no Moodle do IF com o auxílio de uma estudante com deficiência visual e, por fim, faz-se uma reflexão acerca dos resultados com a finalidade de contribuir para as adaptações ainda necessárias nesse ambiente de forma a promover a melhor acessibilidade para os estudantes com deficiência visual.

\section{ANÁLISE DO MOODLE DO IFRN COM O APLICATIVO WAVE}

A pesquisa foi desenvolvida em duas etapas, a primeira, no segundo semestre de 2018, buscou fazer uma análise do Moodle disponível no IFRN. A segunda etapa foi realizada no primeiro semestre de 2019 com a participação de uma estudante com deficiência visual, que colaborou como consultora da análise, testando a usabilidade do ambiente a partir de sua experiência pessoal. 
Na primeira etapa, utilizou-se para esta análise o aplicativo WAVE (sigla em inglês para Web Accessibility Evaluation Tool). O WAVE é uma ferramenta que auxilia os desenvolvedores a tornar seu conteúdo da Web mais acessível. Os desenvolvedores do aplicativo deixam claro que o WAVE não pode dizer se seu conteúdo da web está acessível, ressaltando a necessidade de serem realizados também testes com seres humanos para determinar a acessibilidade real. Entretanto, 0 WAVE pode auxiliar a avaliar a acessibilidade dos conteúdos de uma página web (WAVE, 2018).

Três testes foram realizados utilizando o aplicativo no Moodle do IFRN após a instalação de uma extensão para navegador web deste aplicativo. O primeiro deles na página inicial de login, o segundo na página inicial após 'logado' e o terceiro numa página de disciplina. Ao total, o sistema identificou 12 erros no próprio código-fonte do Moodle, sendo 2 deles na primeira tela de acesso, 4 na página inicial após o usuário estar 'logado' e 6 em uma página de disciplina formal. Para os problemas de contraste foram detectados 115 erros, sendo 5 na página de login, 60 na página inicial e 50 na página de uma disciplina. A Figura 1 abaixo demonstra como o aplicativo realiza o diagnóstico na página inicial.
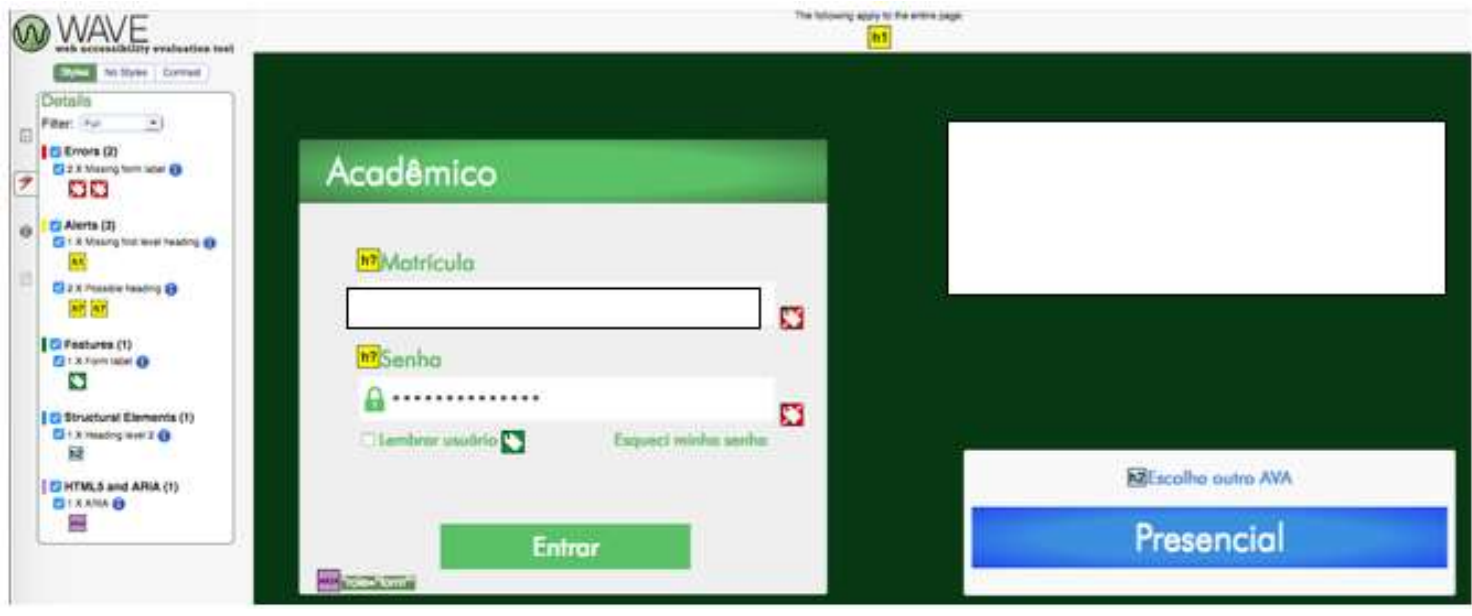

Figura 1: Página inicial analisada pelo aplicativo WAVE.

Fonte: https://ead.ifrn.edu.br/ava.

Os erros apontados na página inicial estão ligados à ausência de label no formulário de acesso. Se um controle de formulário não apresentar um label com o texto associado adequadamente, a função ou o propósito desse controle de formulário não poderá ser apresentado aos usuários de leitores de tela. Os rótulos de formulário também fornecem descrições visíveis e metas clicáveis maiores para controles de formulário. Esse aspecto é algo que pode ser resolvido de forma simples pelos desenvolvedores.

A página inicial também apresenta 4 problemas de natureza simples a serem solucionados. O primeiro deles também ligados ao label, de uma barra de pesquisa superior utilizada para realizar pesquisas em todo o site. Como o input de pesquisa não apresenta a descrição, pessoas que 
utilizam leitores de tela não entenderão o seu significado. Abaixo segue a Figura 2 que mostra como o aplicativo WAVE identificou a ausência deste atributo.

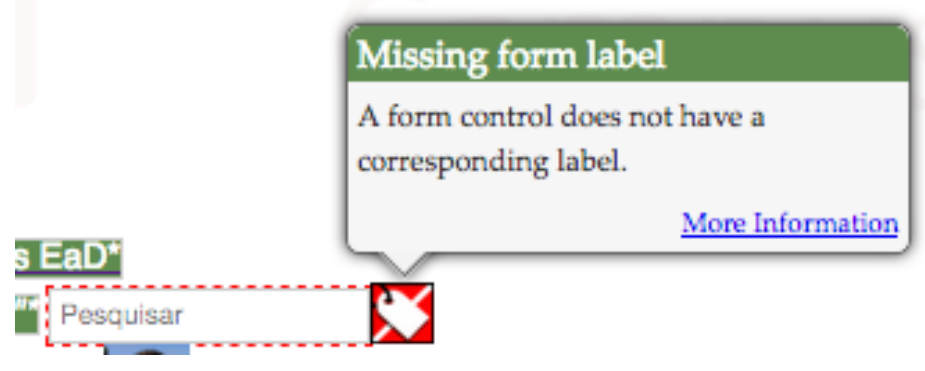

Figura 2: Ausência de label identificada pelo aplicativo WAVE.

Fonte: https://ead.ifrn.edu.br/ava/.

O erro seguinte apresentado pelo aplicativo também é de uma descrição simples no códigofonte agora referente ao atributo aria-labelledby. O ARIA (sigla em inglês para Accessible Rich Internet Application) é uma tecnologia complementar para o HTML5 e ele provê uma ontologia de funções, estados e propriedades que especificam elementos acessíveis de interface. Em suma, ele estende a semântica do HTML fornecendo informações sobre widgets, estruturas e comportamentos, de modo a possibilitar que tecnologias assistivas reconheçam e transmitam informações adequadas. O atributo aria-labelledby - que foi diagnosticado com problemas pelo WAVE - é usado para indicar os IDs de elementos que são os rótulos para o objeto. Ou seja, é utilizado para estabelecer uma relação entre widgets ou grupos e suas labels. Os indivíduos que fazem uso tecnologias assistivas como leitores de telas navegam tipicamente uma página utilizando o botão $T A B$ do próprio teclado entre as áreas da tela. Se uma label não está associada com um elemento input, widget ou grupo, não será legível por leitor de tela. No caso, o problema deste atributo também está relacionado a uma descrição para ser lido de forma adequada pelo leitor de tela, já que o sistema identificou a existência do atributo, entretanto ele não está devidamente identificado em uma instância da página. A Figura 3 a seguir mostra como o WAVE identificou um problema neste elemento no Moodle do IFRN.

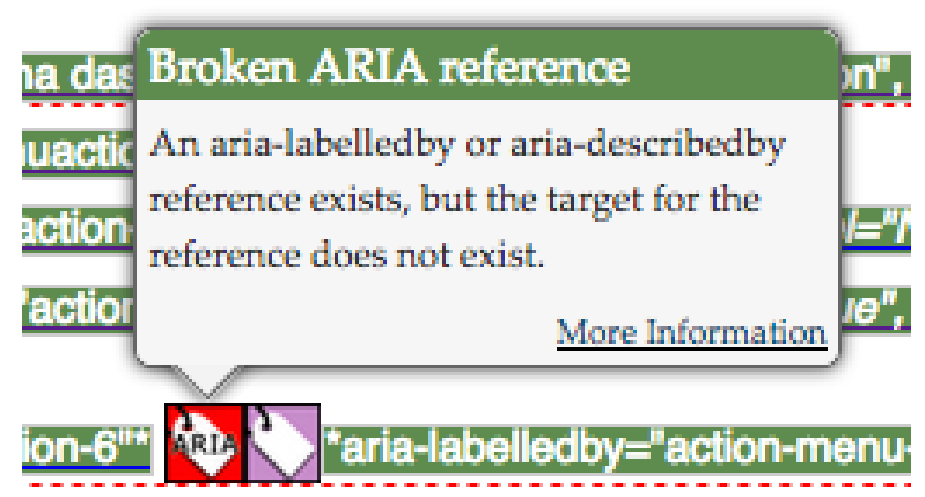

Figura 3: Leitura do aplicativo WAVE para referência da aria-labelledby. Fonte: https://ead.ifrn.edu.br/ava/ 
Os dois erros seguintes são de links vazios nos botões de mensagens e notificações do AVA. Quando um link não contém texto, a função ou finalidade do link não será apresentada ao usuário. Isso pode causar confusão para os usuários de teclado e leitor de tela. Sendo facilmente solucionado removendo o link vazio ou fornecendo texto no link que descreve a funcionalidade e/ou o destino desse link. A Figura 4 ilustra a leitura do aplicativo para este problema.

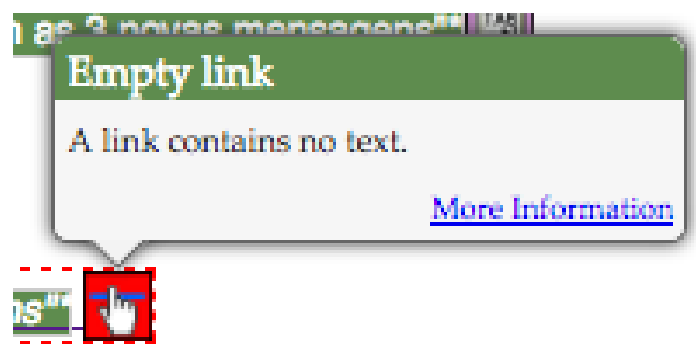

Figura 4: Link vazio identificado pelo WAVE. Fonte: https://ead.ifrn.edu.br/ava/.

A página de uma disciplina identificou seis erros sendo um de label de formulário, três de links vazios e dois de referência do tipo ARIA já explicados anteriormente. Portanto, a resolução desses problemas pode ser realizada de forma similar.

Um aspecto importante que deve ser levado com maior esmero está ligado às ferramentas de contraste do sistema, pois foram identificados 115 erros nas três páginas analisadas e que necessitam um trabalho maior, já que estão relacionados ao fato de que as páginas, seu layout e escolha dos estilos não foram selecionados com esta finalidade, mas, sim, utilizando as cores mais ligadas à identidade institucional do IF. Acreditamos que a melhor solução neste sentido seria desenvolver um template de página para o Moodle (ou utilizar um existente na comunidade) que conteúdos sejam apresentados com uma seleção de cores que trabalhe melhor estas características. A Figura 5 a seguir ilustra como o WAVE identifica os problemas de contraste do Moodle na página de uma disciplina com as marcações em vermelho. 


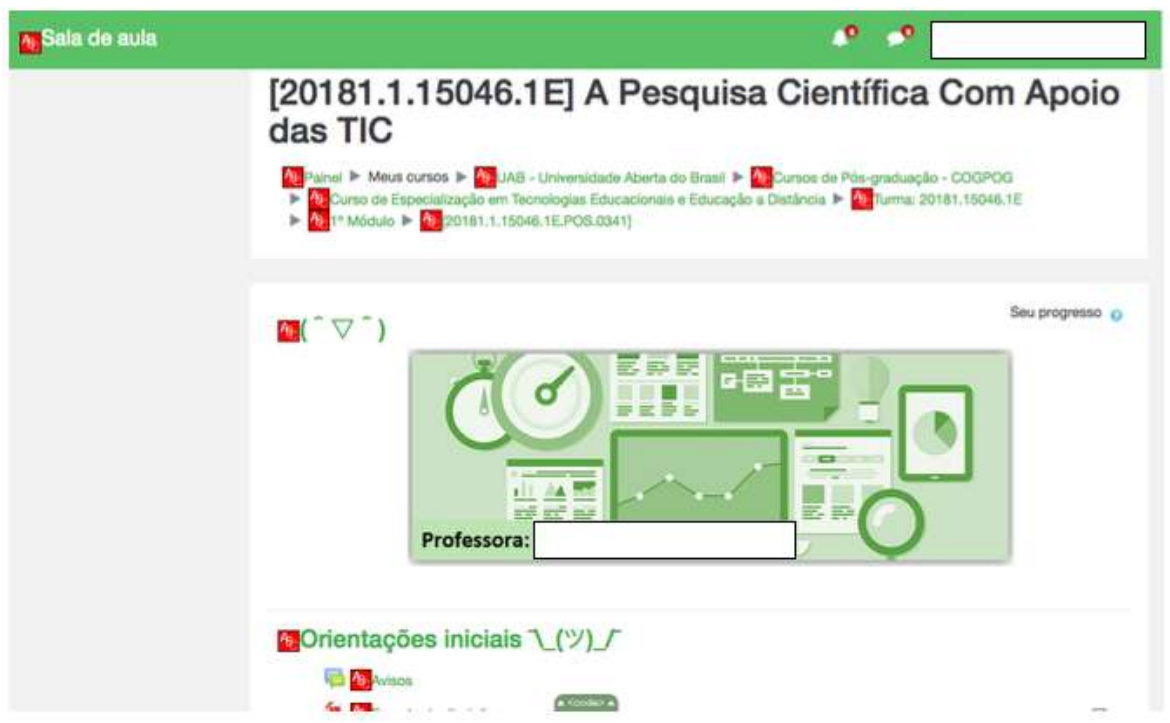

Figura 5: Problemas com contraste identificados pelo WAVE.

Fonte: https://ead.ifrn.edu.br/ava/.

O aplicativo oferece a opção de dessaturação da página (conversão em um cinza com maior ou menor intensidade em seu mesmo valor) para auxiliar no trabalho com contraste. A Figura 6 ilustra esta opção no sistema.

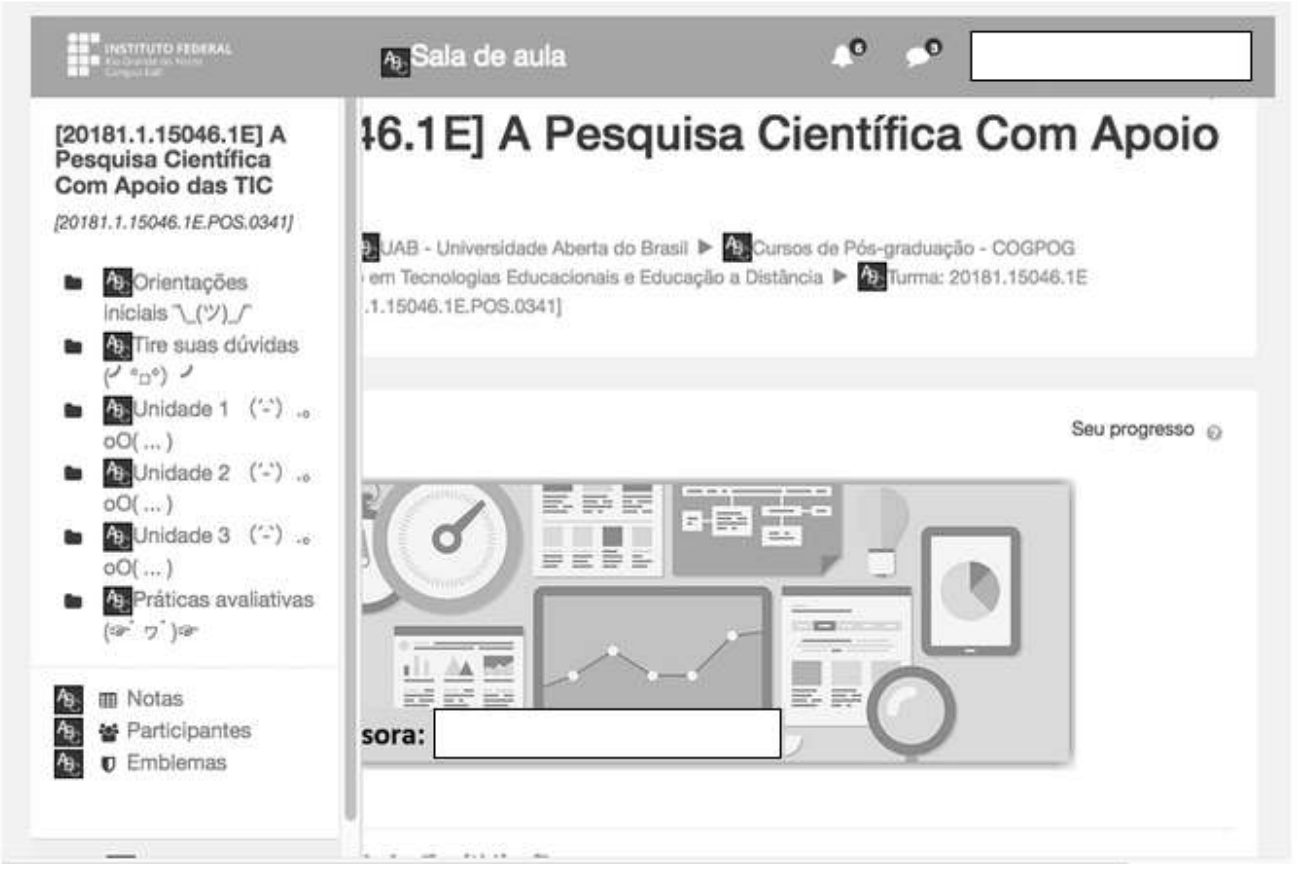

Figura 6: Página com efeito de dessaturação.

Fonte: https://ead.ifrn.edu.br/ava/.

Os testes da plataforma utilizando as ferramentas indicadas apresentaram resultados que condizem com a sua acessibilidade, embora ainda necessitando de ajustes para o uso mais autônomo dos estudantes com deficiência visual. Dessa forma, se mostrou necessária a 
colaboração e consultoria da estudante com deficiência visual na testagem da usabilidade da plataforma.

\section{TESTE DE ACESSIBILIDADE DO MOODLE COM ALUNA}

O teste ocorreu no laboratório de informática do Campus Zona Leste do IFRN. A estudante inseriu a seguinte observação no seu cadastro acadêmico no Sistema Unificado de Administração Pública (SUAP): "Candidata portadora de deficiência visual a qual o laudo médico apresentado descreve como: "acuidade visual percepção à luz no olho direito e sem percepção luminosa no olho esquerdo devido a um tumor vascular coriorretiniano em ambos os olhos, com aspecto irreversível (CID 10 H54). Faz uso de programa de computador que fala o que está escrito (NVDA), e através deste veículo pretende realizar o curso"."

A estudante realizou o teste junto às professoras da área de tecnologias. Foi esclarecido a ela o objetivo da pesquisa naquele momento: testar algumas funcionalidades do Moodle e que em nenhum momento a aluna estava sendo avaliada, mas estava sendo convidada a colaborar como consultora da usabilidade daquela plataforma. Portanto, foi esclarecido que ela não teria que se preocupar em "cometer possíveis erros". Logo após foi esclarecido que as professoras gostariam de ouvir exatamente o que a aluna estava pensando sobre o teste e sobre os recursos e atividades que seriam analisados por ela. $O$ objetivo dessas explicações era deixar a aluna ciente de que ela poderia falar o que estava pensando honestamente e em voz alta no sentido de ajudar a equipe a perceber sua análise e poder propor melhorias no ambiente virtual.

Além disso, foi esclarecido que ela poderia fazer perguntas, mas que talvez as pesquisadoras não pudessem responder por fazer parte do teste, em que é necessário averiguar como as pessoas se saem no manuseio do sistema quando não tem ninguém ao lado delas, mas que as pesquisadoras tentariam responder ao final dos testes caso a aluna achasse necessário. Também foram explicadas as formas como o teste seria registrado, por meio de uma câmera, onde suas expressões faciais, reações e emoções estariam sendo registradas, bem como a gravação da tela com todos os movimentos de navegação. A aluna aderiu ao processo e se prontificou a colaborar de forma ampla com essa análise.

Para efeito de manter as questões ligadas à ética em pesquisa, também foi solicitada a autorização por meio da assinatura de um Termo de Consentimento Livre e Esclarecido (TCLE) possibilitando o uso dos dados do teste para os fins da pesquisa e, caso houvesse publicação em algum local como congresso ou revista acadêmica, a garantia de ser preservada sua identidade, assim como a garantia de que a finalidade seria totalmente para fins acadêmicos e científicos. $O$ termo foi lido em voz alta para a aluna e ela fez a assinatura para dar início ao teste. A aluna entendeu todo o procedimento e não fez nenhuma pergunta. 
Antes de interagir com a página, houve uma conversa no sentido de conhecer melhor a rotina da estudante e seu letramento com as tecnologias. Nessa conversa foi solicitado que a estudante se apresentasse, informando nome completo, formação e se ela estava trabalhando e em quê. A aluna se encontrava no 5o período do curso de Licenciatura em Espanhol e não estava trabalhando.

Também foi solicitado que ela descrevesse um dia típico em seu cotidiano e ela indicou que além do tempo dedicado aos estudos, também auxilia a mãe nos afazeres domésticos e costuma dedicar parte do dia em ir à igreja. Ao ser indagada quais os sites que ela mais gostava de acessar, como redes sociais, a aluna descreveu que antes gostava de acessar a rede social Twitter, mas havia mudado para se dedicar mais aos estudos. No caso do IFRN, se dedicava mais ao acesso ao Ambiente Virtual de Aprendizagem Moodle.

Acerca do nível de compreensão dos recursos disponíveis no leitor de tela NVDA, ela disse que tem um bom conhecimento, numa escala de 1 a 10 sendo 1 nenhum entendimento e 10 entendimento total da ferramenta, a aluna se identificou com a nota 8. Ainda acrescentou que acha o NVDA a solução mais atualizada e completa para o seu trabalho.

A aluna afirmou que estar matriculada em um curso EAD era algo vantajoso, era o primeiro curso da modalidade que ela fazia e destacou a praticidade em realizar o curso de casa. Também mencionou as dificuldades em depender dos pais para sair de casa, pois possui pouca independência no sentido de se deslocar de um local para outro. As disciplinas que ela mais gostou de cursar foram as voltadas para o próprio idioma espanhol. Já as que teve maior dificuldade foram as de Fonética e Fonologia. Ela argumentou que a disciplina tinha muitas imagens, o que dificultava a leitura adequada, como por exemplo as do aparelho fonador. Outra dificuldade apontada pela aluna se dava em relação ao sistema leitor de tela não dispor de recursos adequados para trabalhar com questões de fonética e fonologia como entonação, melodia, aspectos próprios da língua espanhola. A aluna explicou que é possível modificar o sintetizador, mas que essa mudança pouco poderia auxiliá-la nesse quesito.

Após as questões iniciais, foi dado início aos testes práticos na página. Primeiramente foi solicitado que a aluna entrasse no sistema utilizando suas credenciais de estudante. Ela mencionou que ela acessa no seu computador e, portanto, a primeira tela de login já tem esses dados previamente salvos. Como o teste foi realizado em computador com que ela não estava habituada, ela teve uma pequena dificuldade com o uso do teclado (diferente do seu), mas a dificuldade foi contornada.

Ela disse que as dificuldades de leitura que ela teve ocorreram no início do curso, mas após se habituar e salvar as credenciais no seu computador, esse acesso inicial foi facilmente superado. Também mencionou a experiência com outras redes como o Twitter, que fazem com que ela tenha uma certa facilidade de lidar com o Moodle. Acerca da página inicial com a lista dos cursos, ela destacou que, ao fazer a leitura dessa página, ela primeiro prefere fazer uma leitura das mensagens 
não lidas/recebidas. Durante o teste, sem maiores dificuldades conseguiu perceber que tinha 21 mensagens não lidas e conseguiu responder uma mensagem de teste enviada pela professora.

Logo após foi solicitado que a aluna acessasse o link de notificações da página. Vale destacar que o ícone de notificações fica ao lado da opção de mensagens e a aluna informou no teste que nunca tinha conseguido acessá-lo. Como esta funcionalidade existe para que a aluna saiba o que há de recente no ambiente virtual em relação às disciplinas em que está cadastrada, é um aspecto a ser observado para ser melhorado no ambiente. Ela esclareceu que consegue visualizar a quantidade de mensagens enviadas, mas as notificações não. Num segundo momento, durante os testes, ela percebeu a existência de notificações, mas não ficou claro o local exato para ela, se era um ícone que poderia se desdobrar em outros conteúdos pertinentes. Portanto, pode ser concluído que o recurso de notificações merece uma melhor adequação para pessoas com DV. A Figura 7 mostra como surgem na tela as notificações e mensagens.

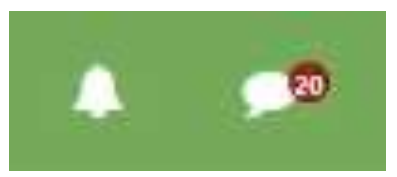

Figura 7: Ícones de notificação na página e mensagens. Fonte: https://ead.ifrn.edu.br/ava/

Vale ressaltar que o problema de link vazio foi verificado no teste com o WAVE tanto para as notificações quanto para as mensagens, mas apenas foi um fator de dificuldade para a aluna na funcionalidade de verificação das notificações. Outro problema que foi diagnosticado no WAVE, mas que foi pouco percebido pela aluna se deve ao ARIA com o nome e imagem da usuária, pois ela demostrou ter realizado a leitura daquela sessão sem dificuldades quando solicitada.

Após isso, foi solicitado que a aluna entrasse em página específica pré-configurada para a realização dos testes de acessibilidade. Ao questionar sobre o que mais chama atenção na página de uma disciplina e o que normalmente a aluna faria num primeiro acesso, ela enfatizou que de início sempre procura pelo material didático da disciplina e pelas atividades em aberto, que precisam ser realizadas e enviadas.

Logo em seguida foi solicitado que a aluna fizesse a leitura do cabeçalho da página com uma imagem que tinha a seguinte descrição: "Imagem representando uma mesa de estudos com computador com braços por cima do teclado e mouse, tablet, anotações, celular e copo de café. Ao final texto com o nome da professora". A aluna não demonstrou nenhuma dificuldade de compreensão do que a imagem representava. O que significa que a descrição, da forma como apresentada naquele momento, foi suficiente para compreensão do que aquela imagem significava no contexto da disciplina.

A seguir foi solicitado que a aluna acessasse um fórum geral destinado às dúvidas e postasse um comentário de teste após a leitura. O objetivo era verificar como se daria a leitura do botão de acrescentar um novo tópico de discussão. A aluna não demonstrou dificuldades em interagir com HOLOS, Ano 36, v.4, e9219, 2020 
este tipo de atividade. Em outro momento foi solicitado que a aluna acessasse outro fórum, dessa vez avaliativo e com o formato de discussão simples, e a aluna também não apresentou dificuldades na interação.

Outro passo de interação sem dificuldades foi com um recurso ${ }^{2}$ do tipo página, que continha informações sobre o cronograma das atividades em formato de tabela. Previamente nos foi notificado que a aluna tinha dificuldades em ler conteúdos neste tipo de formato, compreendendo colunas e linhas, inclusive em alguns momentos foi recomendado que os professores utilizassem listas ou outra estrutura para que a aluna não tivesse dificuldades. Entretanto, pelo teste pôde ser percebido que a aluna não tem problemas de leitura com o NVDA. Além disso, neste teste em específico, ela compreendeu de forma favorável a tabela. Logo tem-se como conclusão que o mais adequado seria trabalhar a leitura crítica de textos neste formato, ao invés de simplesmente não os disponibilizar. Pois, em inúmeros outros contextos dentro e fora da sala virtual a aluna, como qualquer outra pessoa com DV ou não, irá se deparar com tabelas. É importante, portanto, saber interpretá-las de forma adequada em qualquer situação ao invés de simplesmente suprimi-las.

Em seguida foi solicitado que a aluna acessasse o recurso livro ${ }^{3}$, que tinha conteúdos sobre a EaD no instituto. O livro continha três páginas e foi constatado que a aluna sentiu dificuldades em acessar as demais páginas que não eram a inicial do recurso. Atualmente a forma como a paginação se encontra estruturada contém os links de próxima página e página anterior, entretanto a compreensão de que esses links trariam alguma continuidade para o material por hora disponibilizado não foi alcançada da melhor forma. Após a indicação de que esse material tinha mais de uma página, a aluna conseguiu fazer a leitura correta. A estrutura anterior deste material disponibilizava um link lateral com todos os capítulos e subcapítulos do livro. Uma possível solução para este problema seria manter a estrutura anterior deste recurso. A Figura 8 ilustra o recurso do tipo livro com os links mencionados.

\footnotetext{
${ }^{2}$ Os recursos no Moodle podem ser compreendidos como "uma forma de o professor disponibilizar conteúdos e estruturar a página de um curso. Difere das atividades porque os recursos são disponibilizados no sistema, porém ainda não há uma estrutura de avaliação" (SANTOS, LEMOS e BEZERRA, 2012, p. 155).

${ }^{3} \mathrm{O}$ recurso do tipo livro no Moodle possibilita criar um recurso, dentro da própria plataforma, com diversas páginas, de forma que esse recurso possa ser dividido em capítulos e subcapítulos.
} 


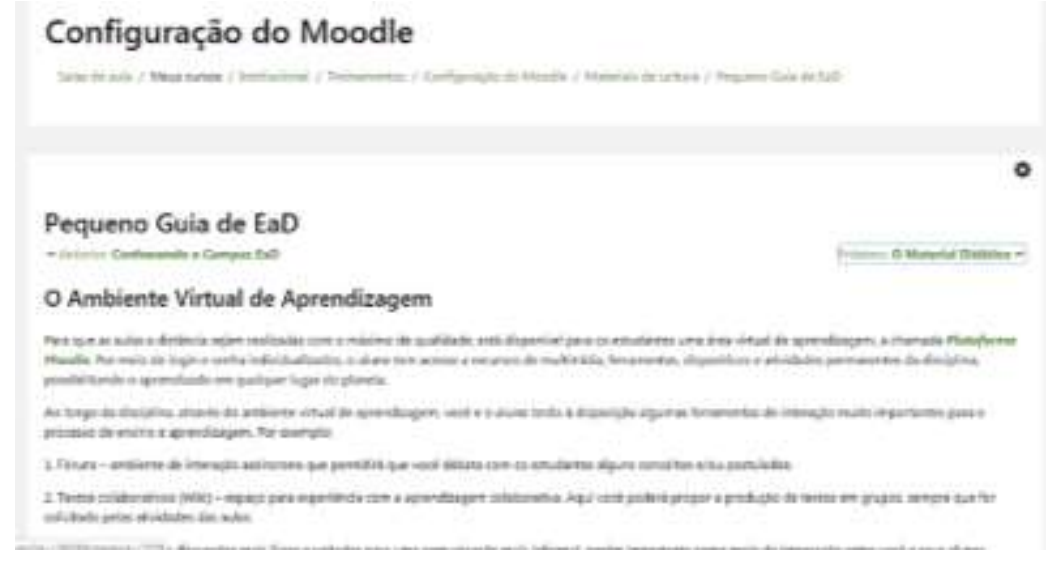

Figura 8: Recurso livro com links para página anterior e posterior.

Fonte: https://ead.ifrn.edu.br/ava/

Outro problema constatado foi percebido ao solicitar que a aluna tentasse fazer o download de um arquivo e tentasse fazer a leitura. Como a aluna estava em um ambiente configurado para acesso dos alunos e funcionários do campus em rede, ela teve dificuldades em acessar o caminho para a pasta de Downloads. Uma solução para que a aluna tenha mais autonomia em utilizar os recursos do computador seria a inserção de ícones de atalho na área de trabalho que direcionassem diretamente às pastas mais comumente acessadas, como a de Downloads, por exemplo.

Foi perguntado qual a forma que a aluna se sente mais confortável em acessar os arquivos, se seria fazendo o download ou se eles abrissem dentro do próprio sistema Moodle. A aluna disse que prefere fazer o download para estudar sem estar conectada. Inclusive porque em alguns momentos no ambiente virtual esse material fica oculto, como em momentos de avaliações presenciais, por exemplo. Com isso, e pelo fato de ela já ter realizado o download prévio, ela consegue ter um acesso mais facilitado.

Ao final foi perguntado como se dá a relação da aluna com o NAPNE, a aluna informou que aparece a opção de acesso à página no sistema, entretanto, ela ainda não tinha realizado o acesso porque havia uma professora que realizava atendimento direto a ela via WhatsApp e troca de mensagens no Moodle. O que leva a concluir que a atuação do NAPNE naquele contexto de atendimento à aluna não se fez necessário por ter outro acompanhamento mais individualizado. Além disso, foi perguntado à aluna se ela tem alguma outra dificuldade com os recursos e atividades do Moodle e a aluna relatou que tem dificuldades de responder questionários com as perguntas do tipo: associação de colunas, preencher lacunas e o sistema de sorteio e mistura entre as questões. Foi informado então que seriam desenvolvidos novos testes para averiguar esses e outros pontos em profundidade com a aluna. 


\section{RECOMENDAÇÕES PARA UTILIZAÇÃO ADEQUADA DE ALGUNS RECURSOS E ATIVIDADES DO MOODLE}

Os estudantes com DV dos cursos EaD do IFRN utilizam o software leitor de tela NVDA (NonVisual Desktop Access) como tecnologia assistiva para acessibilidade do Moodle e materiais didáticos. O NVDA possibilita o uso de sistemas Windows e aplicativos, tem Licença Pública Geral - Versão 2, com download gratuito, requerendo Memória RAM mínima de: 256 Mb ou mais e Processador de no mínimo 1.0Ghz.

Atualmente o NVDA tem tradução em cerca de 20 idiomas, incluindo o Português Brasileiro e o Espanhol, com várias opções de configuração de voz, como velocidade, tom, pronúncia de pontuação, bips em letras maiúsculas, etc.

Vale salientar que o NVDA descreve as telas do computador através de audiodescrição, ou seja, descreve os elementos textuais e do sistema, mas, no caso de imagens, o software somente identifica-as caso haja a inserção do texto de audiodescrição na própria imagem.

Assim, um elemento fundamental, para o professor, é fazer a descrição adequada ao inserir uma imagem, de qualquer natureza, em sua página, em suas atividades, em seus exercícios, inclusive nas avaliações. A descrição adequada pode ser entendida como aquela que indica o tipo de imagem inserida (uma charge, um cartoon, uma tirinha, por exemplo) e o conteúdo da imagem, sem necessariamente interpretar o sentido do que o texto expressa, de forma a deixar a interpretação para o próprio estudante. $O$ tópico a seguir irá detalhar um pouco mais sobre o uso de imagens, sua descrição e o Moodle.

\subsection{Uso de imagens no Moodle}

A maioria dos recursos, atividades e demais configurações do Moodle utilizam o editor de texto Atto, um editor JavaScript feito especificamente para o Moodle. No Moodle da versão $2.6 \mathrm{e}$ anteriores, TinyMCE era o editor utilizado, entretanto hoje o editor anterior e um editor de texto simples também coexistem. As Figura 9 e 10 ilustram o exemplo de um editor do Moodle na versão 2.6 e versões anteriores e o novo editor respectivamente.

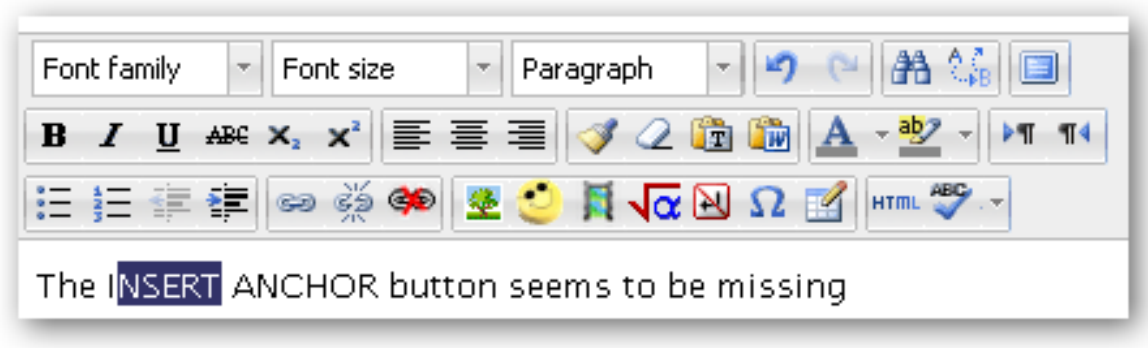

Figura 9: Editor do Moodle versão 2.6 e anteriores. Fonte: https://moodle.org/mod/forum/discuss.php?d=207682 


\section{罦

$A_{A}=$ B $I$ :

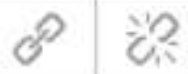

\section{Apresentando o Novo Editor Atto do Moodle}

Figura 10: Novo editor do Moodle.

Fonte: https://codely.com.br/saiba-como-utilizar-o-novo-editor-atto-do-moodle-27-28/

A acessibilidade para imagens, quando se trata de deficiência visual, requer um trabalho mais cauteloso no que se refere à descrição das imagens. Para inserir uma imagem é preciso clicar em botão específico do editor que irá habilitar a opção de inserir a imagem e adicionar a descrição de forma semelhante à Figura 10 abaixo:

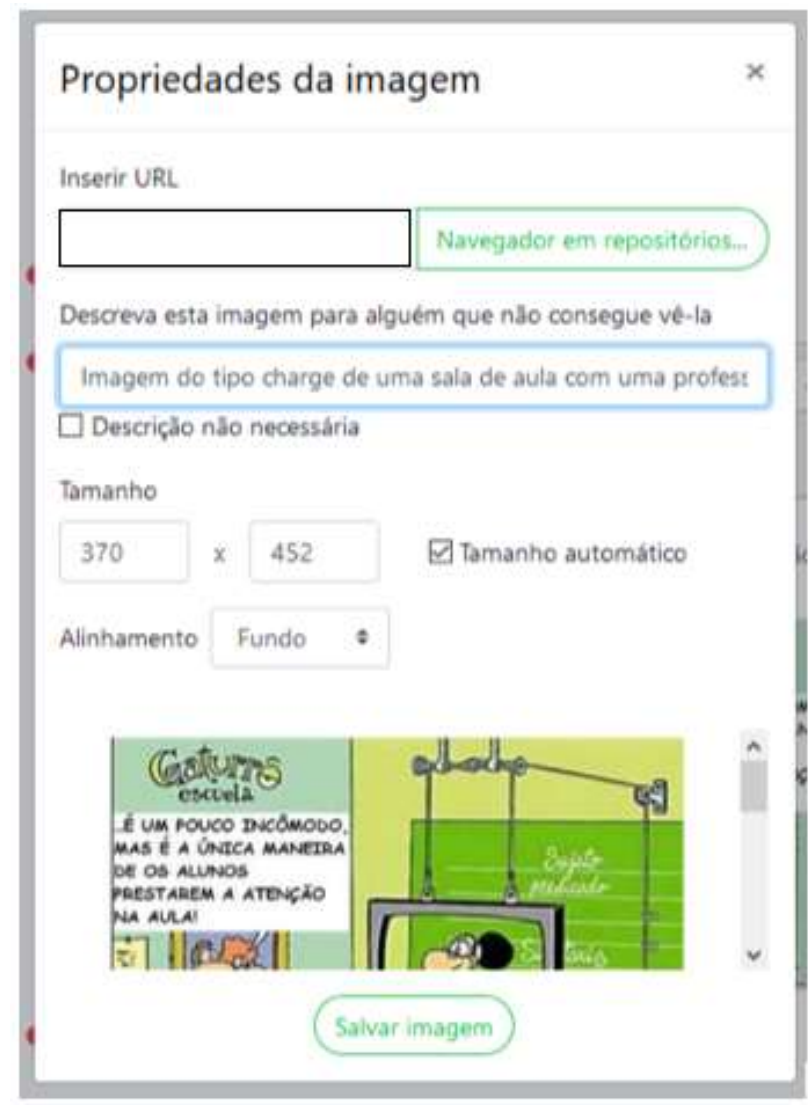

Figura 11: Propriedades da imagem no Moodle. Fonte: https://ead.ifrn.edu.br/ava/

Importante mencionar a necessidade de informar o tipo de imagem que está sendo descrita para o estudante, qual o seu gênero textual. Informar se a imagem é do tipo charge, cartum, tirinha, caricatura, entre outros tipos. Essa informação prévia irá auxiliar o indivíduo que está 
ouvindo a descrição a compreender a intencionalidade da imagem no contexto que está sendo inserida. A Tabela 01 a seguir explica alguns tipos de imagens.

Tabela 01: Gêneros para imagens e finalidade.

\begin{tabular}{c|c}
\hline Imagem & Finalidade \\
\hline Charge & $\begin{array}{c}\text { Realiza uma sátira (crítica sarcástica) de situações específicas, situadas } \\
\text { no tempo e no espaço. É comum que os personagens das charges } \\
\text { sejam personalidades públicas. Por exemplo, pode ser um político, } \\
\text { artista, ou outra figura pública. }\end{array}$ \\
Tirinha & $\begin{array}{r}\text { Consiste numa espécie de anedota gráfica sobre o comportamento } \\
\text { humano. De maneira geral, aborda situações que poderiam acontecer } \\
\text { em qualquer tempo ou lugar, de forma a satirizar os costumes } \\
\text { humanos. Entretanto, este tipo de gênero não faz referência a uma } \\
\text { personalidade em específico. }\end{array}$ \\
\hline Caricatura & $\begin{array}{c}\text { É um tipo de desenho que representa um personagem da vida real, } \\
\text { como políticas e artistas. Este tipo de representação é feita de forma } \\
\text { mais exagerada de características ou hábitos da pessoa em questão } \\
\text { de uma forma humorística. }\end{array}$ \\
\hline
\end{tabular}

Fonte: https://www.estudokids.com.br/charge-cartum-tirinha-e-caricatura-entenda-as-diferencas/

Por exemplo a charge a seguir foi utilizada num questionário no Moodle aplicado com alunos videntes e não videntes. Observe a pergunta com a imagem (Figura 12) e em seguida a sua descrição para ser interpretada pelos leitores de tela: 


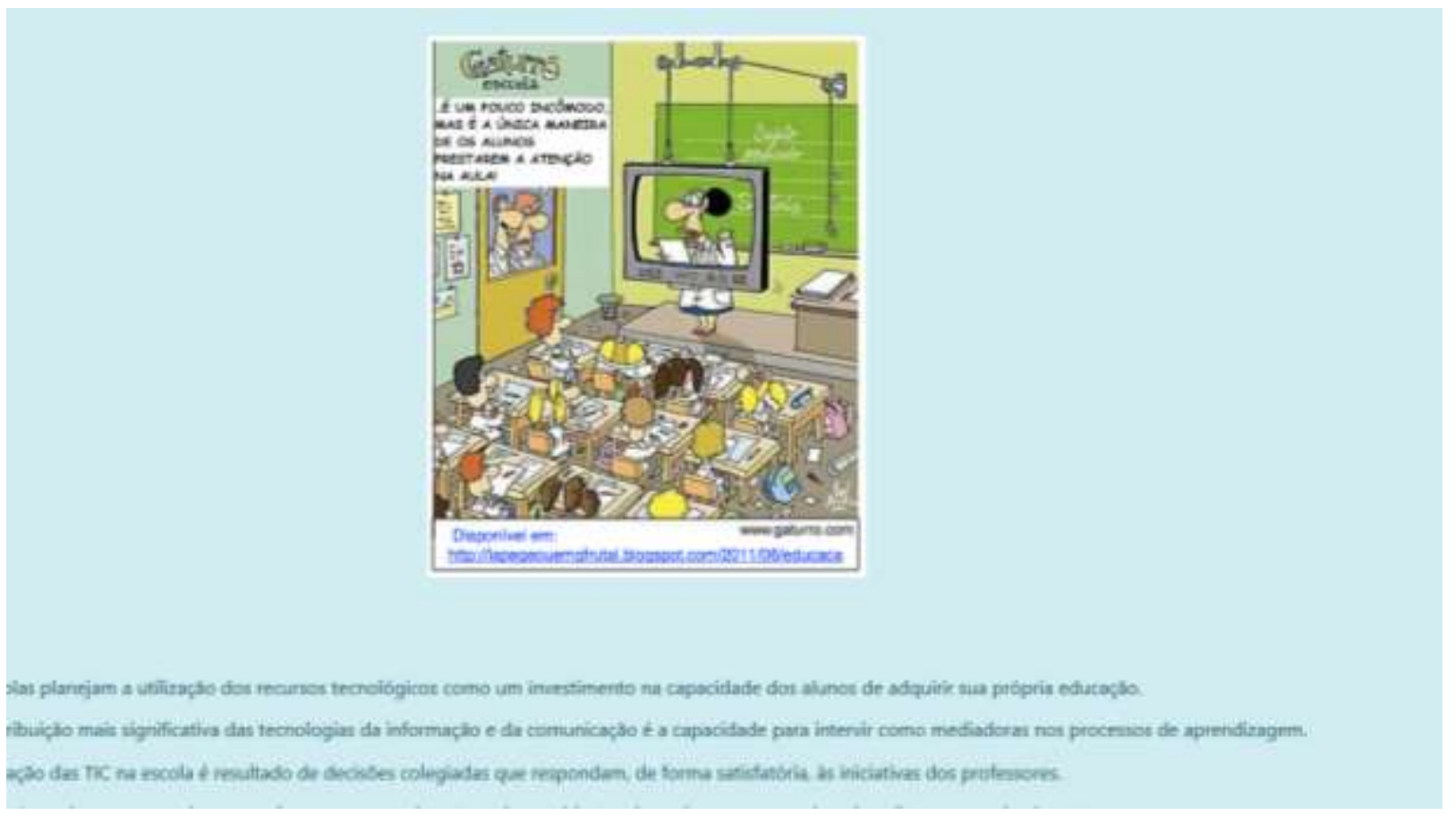

Figura 12: Questão no Moodle.

Fonte: https://ead.ifrn.edu.br/ava/

Observando a pergunta com a imagem (Figura 12) e, em seguida, a sua descrição para ser interpretada pelos leitores de tela, um aluno vidente consegue facilmente interpretar o texto (verbal e visual) e responder o questionário. Para uma estudante com DV, no entanto, faz-se necessária uma descrição. A descrição utilizada para esta imagem foi: "Imagem do tipo charge de uma sala de aula com uma professora atrás de uma moldura em formato de monitor dando aula em uma sala de aula presencial convencional com carteiras e quadro branco para um grupo de alunos. Alguns dos alunos estão prestando atenção, um aluno está dormindo, outros se encontram desatentos. Na porta da sala, do lado de fora, dois funcionários observam e um deles diz: "É um pouco incômodo, mas é a única maneira de os alunos prestarem atenção na aula!".

A análise realizada nas duas etapas apresentadas ao longo deste artigo são os primeiros passos para a compreensão das dificuldades e dos obstáculos ao acesso de estudantes com deficiência visual, no entanto, já apontam para a necessidade de modificações não só no ambiente virtual Moodle utilizado pelo IFRN, mas para a capacitação dos docentes no tocante à melhor utilização dos recursos disponíveis no ambiente, seja na organização das atividades avaliativas (caso dos questionários, por exemplo), seja na descrição acurada das imagens utilizadas na disciplina.

\section{CONSIDERAÇÕES FINAIS}

A análise apresentada ao longo deste artigo é evidentemente algo pontual e transitório, não só porque realizado em um determinado momento do tempo, mas porque realizada com um indivíduo e condicionada às suas singularidades. A plataforma Moodle está em constante 
atualização, mas ela retrata aspectos pertinentes ao uso da plataforma pelos deficientes visuais. A análise ainda pode ser ampliada levando em conta outras instâncias, realizando outros testes de acessibilidade com indivíduos para averiguar em profundidade outros recursos e atividades como: questionários, enquetes, lição, palavras-cruzadas, por exemplo. Entretanto, os erros identificados pelo WAVE e pelo teste realizado com uma aluna usuária e que não são de contraste parecem ser simples de serem solucionados porque o Moodle no seu código-fonte já se preocupou com muitos aspectos relacionados a padrões WEB para acessibilidade.

Pôde ser constatado que a ferramenta de mensagens e notificações não é trabalhada com um aluno que faz uso de leitores de tela, o que pode ser atribuído aos links vazios identificados pelo aplicativo WAVE, por exemplo. Entretanto, ao desenvolver o mesmo teste com a aluna, foi percebido que o link de mensagens foi acessado sem maiores dificuldades.

Já em relação aos problemas de contraste do Moodle, o teste no WAVE demonstra claramente que o AVA não foi desenvolvido pensando em pessoas com baixa visão, mas buscando utilizar as cores que lembram a identidade visual dos próprios IF. Uma solução simples seria não alterar essa estrutura atual existente para aqueles que não necessitam desta funcionalidade em específico, mas, criar um template novo, ou adaptar um existente que esteja mais bem desenvolvido com estruturas de alto contraste.

Ao realizar buscas no Moodle.org foi encontrado o template Obsidian ${ }^{4}$. Um possível desdobramento para esta pesquisa seria analisá-lo como uma solução para o problema de alto contraste, fazer outros testes de acessibilidade e adaptá-lo para que tenha a identidade visual do IF e seja disponibilizado para os indivíduos que necessitem desta opção. Caso o aluno colocasse a opção no seu perfil do aluno que gostaria do ambiente adaptado a esta necessidade o Moodle se adaptaria com este template, por exemplo.

Já em relação ao uso de imagens, é observado que é feito com pouco cuidado em relação às descrições para os alunos com DV. É preciso descrever bem, seguindo algumas recomendações para que os alunos possam ler este tipo de material de forma crítica. Inclusive deixando claro qual o gênero textual da imagem antes de descrevê-la.

Também pôde ser verificado que os materiais didáticos do curso não têm formatação específica para softwares leitores de tela utilizados pelos estudantes com DV, uma vez que não possuem audiodescrição das imagens e algumas caixas de textos não são lidas pelos leitores de tela, uma vez que estão coladas como imagens.

Assim, os professores e tutores necessitam ser orientados a descrever imagens e/ou outros recursos audiovisuais, para torná-los acessíveis aos estudantes com DV. Em alguns casos, os tutores utilizaram o aplicativo Whatsapp para enviar áudios com as descrições de imagens do material didático, de atividades e de vídeos diretamente para as estudantes. No caso de imagens

${ }^{4}$ URL: https://moodle.org/plugins/theme obsidian. Acesso em 23 de setembro de 2019.

HOLOS, Ano 36, v.4, e9219, 2020 
das páginas das disciplinas no Moodle, os professores utilizaram a caixa de formulário própria de descrição. No entanto, o ideal é que esse material realmente seja adaptado para poder atender às necessidades dos estudantes e para sua utilização da forma mais autônoma possível.

Logo, para que a educação de qualidade seja de fato um direito para todos, é preciso que a infraestrutura, os materiais didáticos e o ambiente virtual estejam devidamente adaptados a todos que deles fazem uso. Independentemente se o usuário aluno esteja com alguma necessidade específica de acesso ou não. Por ora estes foram os resultados até então alcançados, mas esperase que nos próximos passos outros recursos e atividades sejam mais bem avaliados para contribuir com possíveis soluções para o design educacional dos cursos a distância.

\section{REFERÊNCIAS}

ARANHA, M. S. F. (2002). Formando Educadores para uma escola inclusiva: PGM 5 - Adaptações de pequeno porte. Brasil. Disponível em: <http://www.redebrasil.tv.br/salto/boletins 2002/feei/teimp.htm>. Acesso em: 18 de jan. 2019

BRASIL. (2004). Decreto № 5.296 de 02 de dezembro de 2004 - DOU de 03/122004. Disponível em: <http://www.planalto.gov.br/ccivil_03/_ato2004-2006/2004/decreto/d5296.htm>. Acesso em: 18 de set. 2019.

BRASIL. (1988). Constituição da República Federativa do Brasil de 1988. Disponível em: http://www.planalto.gov.br/ccivil_03/constituicao/constituicao.htm Acesso em: 18 de set. 2019.

BRASIL. (2015). Lei n. 13.146/2015. Institui lei brasileira de inclusão da pessoa com deficiência. (Estatuto da pessoa com deficiência). Disponível em: http://www.planalto.gov.br/ccivil_03/_ato2015-2018/2015/lei/I13146.htm Acesso em: 22 de março de 2018.

BRASIL. (2008). Lei no 11.892/2008. Institui a Rede Federal de Educação Profissional, Científica e Tecnológica. Disponível em: http://www.planalto.gov.br/ccivil_03/_ato20072010/2008/lei/l11892.htm. Acesso em: 18 de set. 2019.

IFRN. (2019). Sobre o NAPNE: Núcleo de Apoio às Pessoas com Necessidades Educacionais Específicas. Disponível em: <https://portal.ifrn.edu.br/campus/natalcentral/nucleo-deinclusao >. Acesso em: 26 Set. 2019.

MOZILLA. (2019). Usando o atributo aria-labelledby. Disponível em: $<$ https://developer.mozilla.org/ptBR/docs/Web/Accessibility/ARIA/ARIA_Techniques/Usando_o_atributo_aria-labelledby>. Acesso em: 27 mai. 2018.

MOZILLA.(2019). Using the aria-describedby atribute. Disponível em: $<$ https://developer.mozilla.org/en- 
US/docs/Web/Accessibility/ARIA/ARIA_Techniques/Using_the_aria-describedby_attribute>. Acesso em: 27 mai. 2018.

SANTOS, S. C. A. dos; LEMOS, E. das C.; BEZERRA, C. G. (2012). Curso de formação em EAD. Natal: IFRN.

SCHLÜNZEN JÚNIOR, K.; HERNANDES, R. B. (2011). As dimensões do não ver: formação continuada de educadores e a profissionalização das pessoas com deficiência visual. São Paulo: Editora Unesp.

SKEETE, N. A. (2013). A experiência pioneira do IFRN com reserva de vagas em seus processos seletivos. Coleção J, LPP. Disponível em: <http://memoria.ifrn.edu.br/handle/1044/898>. Acesso em: 27 Set. 2019.

WAVE. (2018) Web Accessibility Evaluation Tool. Disponível em: <http://wave.webaim.org>. Acesso em: 27 mai. 2018.

W3C. (2018) Cartilha de Acessibilidade na Web. Disponível em: <http://www.w3c.br/pub/Materiais/PublicacoesW3C/cartilha-w3cbr-acessibilidade-webfasciculo-I.html>. Acesso em: 27 mai. 2018.

W3C. (2018) Acessibilidade para o WAl. Disponível em: <http://www.w3.org/WAl/intro/accessibility.php>. Acesso em: 27 mai. 2018.

\section{COMO CITAR ESTE ARTIGO:}

Lemos, E.C., Cavalcante, I.F., Almeida, R.P.B. (2020). Análise e diagnóstico da acessibilidade no Moodle para deficientes visuais. Holos, 36(4), 1-23.

\section{SOBRE OS AUTORES}

\section{ELIZAMA DAS CHAGAS LEMOS}

Doutora em Tecnologias e Sistemas da Informação pela Universidade do Minho (Uminho); Professora de Tecnologias Digitais da Informação e Comunicação; Instituto Federal de Educação, Ciência e Tecnologia do Rio Grande do Norte (IFRN).E-mail: elizama.lemos@ifrn.edu.br

ORCID ID: http://orcid.org/0000-0002-8350-1411

\section{ILANE FERREIRA CAVALCANTE}

Graduada em Letras com habilitação em Língua Portuguesa e Inglesa e respectivas literaturas; Mestra em Estudos da Linguagem com área de concentração em Literatura Comparada; Doutora em Educação UFRN; Desde 2006 professora do Instituto Federal de Educação, Ciência e Tecnologia do Rio Grande do Norte (IFRN) onde leciona Língua Portuguesa; Atua no Programa de Pós-Graduação em Educação Profissional (PPGEP-IFRN). E-mail: ilane.cavalcanti@ifrn.edu.br

ORCID ID: https://orcid.org/0000-0002-1783-9879

\section{ROSEMARY PESSOA BORGES DE ALMEIDA}

Mestre em Ciências da Computação (UERN/UFERSA); Professora de Tecnologias Digitais da Informação e Comunicação; Instituto Federal de Educação, Ciência e Tecnologia do Rio Grande do Norte (IFRN). 
E-mail: rosemary.borges@ifrn.edu.br

ORCID ID: http://orcid.org/0000-0002-8522-0824

Editor(a) Responsável: Francinaide de Lima Silva Nascimento Pareceristas Ad Hoc: Carla Araújo e Geisy Venâncio

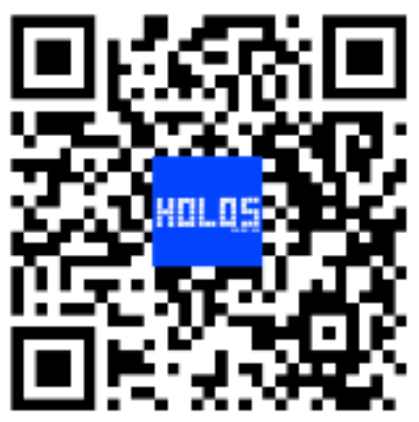

Recebido: 02 de dezembro de 2019 Aceito: 24 de junho de 2020 Publicado: 01 de julho de 2020 